DOI: 10.4274/ejgg.galenos.2020.221

Eur J Geriatr Gerontol 2020;2(2):36-40

\title{
Malnutrition and Related Factors in Older Adults
}

\author{
(1) Nezahat Muge Catikkas \\ Istanbul University Faculty of Medicine, Department of Internal Medicine, Division of Geriatrics, Istanbul, Turkey
}

\begin{abstract}
Objective: Malnutrition is a treatable condition and an important cause of mortality and morbidity in the geriatric population. In this study, we aimed to investigate the risk factors for malnutrition in geriatric patients.

Materials and Methods: Patients aged 65 and over, who were admitted to our center between January 2016 and December 2017, were included in the study. Patients with edema, whose anthropometric measurements could not be performed and who did not agree to participate in the study were excluded from the study. The Mini Nutritional Assessment-Short-Form was used to evaluate nutritional status. The patients were divided into three groups according to nutritional status: normal, with the risk of malnutrition and malnourished. Demographic characteristics and geriatric syndromes were compared between the groups. The chi-square test was used to compare categorical variables, the Mann-Whitney $\mathrm{U}$ test was used to analyze non-parametric variables and logistic regression analysis was done to assess nutritional status.
\end{abstract}

Results: A total of 408 participants (284 female and 124 male) were included in this study. The median age of the patients was 77 years. Malnutrition and the risk of malnutrition were found in $4.9 \%(n=20)$ and $24 \%(n=98)$ of the patients, respectively. There was a significant difference in educational status, functional dependence, urinary incontinence, dementia and depression between malnourished and normal patients. In logistic regression analysis, dementia $(p<0.01$, odds ratio $=4.33)$ was independently associated with malnutrition; whereas depression, gender and functional dependence were not associated with malnutrition.

Conclusion: Our study demonstrated that malnutrition was independently associated with dementia. We suggest that malnutrition and other geriatric syndromes should be screened routinely. Patients with low levels of educational attainment, functional dependence, urinary incontinence, dementia, and depression seem to be at a higher risk of malnutrition and therefore should be paid special attention.

Keywords: Malnutrition, geriatrics, geriatric syndromes

\section{Introduction}

Malnutrition (undernutrition or protein-energy-malnutrition) is a state that can be associated with lack of intake of nutrition caused by diseases (with or without inflammation), socioeconomic, psychologic (disabilities of taste and smell that result in "anorexia of aging") or hunger-related factors and results in a decrease fat-poor body mass and deterioration of body cell components, physical and mental health (1-3). Deficiencies in macronutrients (protein-energy) and micronutrients (vitamins and minerals) are seen very frequently among older adults. Prevalence over 65 years is $9 \%$ to $15 \%$ in outpatient clinics, $12 \%$ to $50 \%$ in hospitalized older persons, and $25 \%$ to $60 \%$ in older adults residing in nursing homes (4).
Malnutrition is a serious cause of increased morbidity and mortality, decreased functionality and quality of life that can be treated and prevented in the geriatric population. In some studies, malnutrition is a predictor of mortality $(5,6)$. In a study, investigating the association between the risk of malnutrition and 7-year mortality, malnutrition increased the risk of mortality significantly (7). It also contributes to increased frequency and length of hospital stay and healthcare costs (8). A prospective study in adults aged over 70 years revealed that adjusted healthcare costs were $714 €$ per year more in patients with malnutrition or malnutrition risk compared to well-nourished patients (9).

Address for Correspondence: Nezahat Muge Catikkas, Istanbul University Faculty of Medicine, Department of Internal Medicine, Division of Geriatrics, Istanbul, Turkey

Phone: +90 2124142000 E-mail: nz444mg@hotmail.com ORCID: orcid.org/0000-0003-2494-1625

Received: 29 Oct, 2019 Accepted: 21 Aprl, 2020

Cite this article as: Catikkas NM. Malnutrition and Related Factors in Older Adults. Eur J Geriatr Gerontol 2020;2(2):36-40

๑Copyright 2020 by the Academic Geriatrics Society / European Journal of Geriatrics and Gerontology published by Galenos Publishing House. 
As malnutrition has been found correlated with Geriatric syndromes, it is important to identify and treat nutritional problems earlier $(10,11)$. Nutritional status can be assessed by standard anthropometric (e.g., skinfold thickness, midarm muscle area, body mass index), biochemical and immunologic (e.g., albumin, prealbumin, transferrin and lymphocyte counts) measures; but they are not preferred because of difficulty to perform these measurements. The most widely used, validated and reliable screening tool for older adults is the Mini Nutritional Assessment-Short-Form (MNA-SF) $(12,13)$.

In this study, we aimed to evaluate the malnutrition and related factors among older patients admitted to our outpatient clinic, due to the increasing prevalence of malnutrition and lack of studies assessing these factors in the Turkish community.

\section{Materials and Methods}

The medical records of patients, aged $\geq 65$ years admitted to the geriatric outpatient clinic in our center between January 2016 and December 2017 were evaluated retrospectively. Four hundred eight patients were included in the study with consent forms. Demographic characteristics (age, gender, ambulation) and geriatric syndromes (urinary incontinence, fecal incontinence, difficulty in swallowing, chewing difficulty, dementia, depression) of the patients were investigated. Patients with edema, whose anthropometric measurements could not be performed and who did not agree to participate in the study were excluded from the study.

The MNA-SF test was used to evaluate nutritional status. MNA consists of 18 questions, 15 of which are based on verbal questioning, 3 of them are based on anthropometric measurement, and scoring is based on 30 points. It has two stages. In the first stage, MNA-SF is used and if there is a risk of malnutrition (if the score is 11 and less out of 14), the second stage is continued with the evaluation section. In our study, nutritional status was divided into three groups according to the MNA-SF scores, as normal nutritional status 12-14 points, malnutrition risk 11-8 points and malnutrition 7 or lower points. Patients were categorized as normal, with the risk of malnutrition and malnourished. Demographic characteristics and geriatric syndromes were compared between the groups. Swallowing and chewing difficulties were assessed by asking the patients if they experienced difficulty in swallowing and chewing. Ambulation status of the patients was questioned and grouped as immobile, walk with help and walk without help. Mini-Mental State Examination (MMSE) and the short and longform geriatric Depression scale (GDS-SF and GDS-LF) were used to assess cognition and depression. The validity of the Turkish versions of the MMSE and GDS-SF has been confirmed $(14,15)$. MMSE scores lower than 24 indicate cognitive impairment and GDS scores greater than 14 indicate depression. This study has been evaluated and approved by the local ethics committee (number: 956).

\section{Statistics}

Descriptions of patient demographic characteristics (age, gender, ambulation) and geriatric syndromes (urinary incontinence, fecal incontinence, difficulty in swallowing, chewing difficulty, dementia, depression) were performed through percentage for qualitative variables. For quantitative variables with normal distribution, the mean standard deviation was used. For variables not following normal distribution median and percentiles were used. The chi-square test was performed for qualitative variables, whereas the Mann-Whitney $U$ test was used for qualitative variables with the nonparametric distribution. Conditional forward method of binary logistic regression analysis was used to establish the relationship between the demographic characteristics, geriatric syndromes, and malnutrition in terms of odds ratio (OR) and 95\% confidence interval. Univariate logistic regression analysis was used to determine the factors related to malnutrition, and multivariate analysis was used for parameters found significant in univariate analysis. All tests were two-tailed, and a $p$ value of less than 0.05 was considered significant. SPSS 15.0 (SPSS Inc., Chicago, IL) statistical software was used to analyze data.

\section{Results}

Four hundred eight participants were included in this study (284 female and 124 male). The median age of the patients was 77 years (minimum $=65$, maximum $=95$ ). Malnutrition and the risk of malnutrition were found in 4.9\% $(n=20)$ and $24 \%(n=98)$ of the patients, respectively. Demographic characteristics and geriatric syndromes of the patients were shown in Table 1. The results of logistic regression analyses were presented in Table 2. Univariate logistic regression analysis demonstrated that dementia and depression were related with malnutrition ( $p<0.01, \quad 0 R=4.33 ; p=0.01,0 R=3.14$, respectively); however in multivariate analysis, only dementia was associated with malnutrition $(p=0.02,0 R=3.27)$.

\section{Discussion}

Malnutrition is a prevalent problem in older age. In our study, the prevalence of malnutrition was found as 4.9\%. Malnutrition prevalence studies conducted in our country showed that 13$28 \%$ of the elderly in the outpatient clinics or living in the community, 25-45\% of the elderly admitted to the hospital, $20-60 \%$ of the hospitalized elderly and $30-70 \%$ of the elderly living in institutions were at risk of malnutrition silinip yerine malnourished or with the risk of malnutrition (16). The reason for a wide range of prevalence may be the different criteria and assessment tools of malnutrition or studying populations with varying residential status (17). However, our malnutrition 


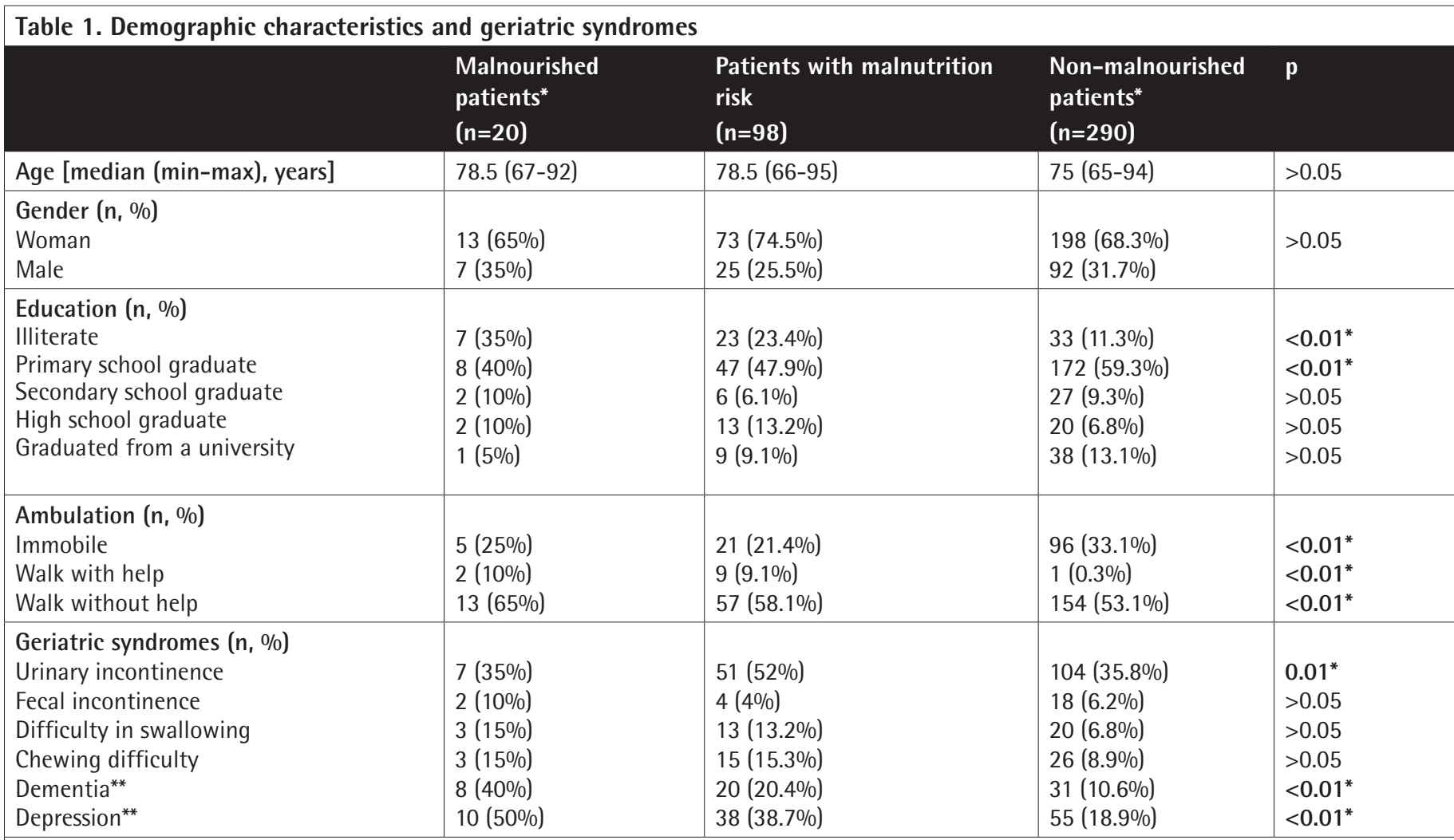

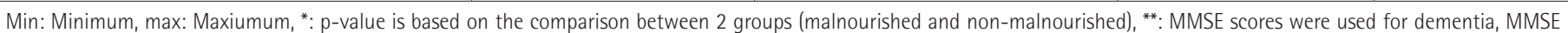
score $<24$ considered as cognitive impairment and GDS scores were used for depression. GDS > 14 considered as depression, MMSE: Mini-Mental State Examination

\begin{tabular}{|c|c|c|c|c|}
\hline \multirow[t]{2}{*}{ Variables } & \multicolumn{2}{|l|}{ Univariate analysis } & \multicolumn{2}{|l|}{ Multivariate analysis } \\
\hline & Odds ratio (Confidence interval) & $\mathbf{p}$ & Odds ratio (Confidence interval) & $\mathbf{p}$ \\
\hline Gender & $1.24(0.48-3.20)$ & 0.64 & - & - \\
\hline Education & $0.75(0.53-1.05)$ & 0.10 & - & - \\
\hline Fecal incontinence & $1.84(0.40-8.47)$ & 0.43 & - & - \\
\hline Difficulty in swallowing & $2.60(0.68-9.69)$ & 0.16 & - & - \\
\hline Chewing difficulty & $1.96(0.52-7.45)$ & 0.32 & - & - \\
\hline Dementia & $4.33(1.70-11.19)$ & $<0.01$ & $3.27(1.19-8.96)$ & 0.02 \\
\hline
\end{tabular}

prevalence is not in accordance with the literature. Identification of malnutrition risk as a separate group may have caused our malnutrition prevalence to be underestimated. Therefore, it is important to screen the nutritional status of older adults living in the community, admitted to the outpatient clinics and to develop a treatment plan through a detailed evaluation of the individuals at risk.

In our study, we found a statistically significant relationship between the malnutrition and urinary incontinence. However, data on this issue are conflicting. Positive correlation of worse nutrition with higher grade of incontinence $(r=0.53, p<0.0001)$ was previously reported (18). On the other hand, in another study, the presence of urinary incontinence was not higher in malnourished patients compared to non-malnourished (19). These converse results can be explained by the differences of the study population, definitions of incontinence and concomitant comorbidities.

In our study, difficulty in swallowing was not interestingly associated with malnutrition. In a study among hospitalized older adults, swallowing disorders are an independent risk factor for malnutrition (20). In another study, 44\% had malnutrition and malnutrition risk correlated with other geriatric syndromes 
in an outpatient clinic (10). On the other hand, the prevalence of swallowing difficulties varies due to gender-related differences, definitions and measurement methods (20). However, we suggest that difficulties in swallowing should be detected and promptly treated.

In our study, we found a statistically significant relationship between dementia and malnutrition and it was similar to the literature. In a study by Soundararajan et al. (19), dementia was significantly higher in malnourished patients compared to nonmalnourished. In another study, also dementia was associated with poor nutritional status (20). Although the types of dementia (e.g. frontotemporal lobar degeneration is generally considered to be associated with overeating) and stages of dementia also had an impact on the results, our results did not include these parameters (21).

Depression is a very common cause of weight loss in older adults and the relationship between those two conditions is interactive. In previous studies, depression was determined as an independent predictor of malnutrition $(17,22)$. In our study, although there was a significant difference between the groups in terms of depression frequency, this difference could not be demonstrated in multivariate logistic regression analysis. The reason for the differences in results may depend on the prevalence of depression in Turkish people and the severity of depression.

In our study, poor educational status and functional dependence also were associated with malnutrition similar to previous studies $(10,17,23)$.

There are several limitations in our study. The sample size was small and the assessment for malnutrition was performed with only MNA-SF. Also, we didn't further analyze the concomitant diseases, other possible related factors with malnutrition (e.g. sarcopenia, frailty, falls, insomnia, etc). Furthermore, the types and stages of dementia and depression were not investigated. Besides, our study mostly represents a geriatric population in outpatient clinics and does not truly reflect the whole population. The differences in our results can be caused by Turkish demographic characteristics, due to these reasons, the results cannot be generalized to all geriatric patients. Also, our results may have been biased since some of the data was based on personal statements. Although malnutrition is a highly prevalent medical burden and known to cause many poor health outcomes, there are a few studies evaluating the prevalence of malnutrition and possible related factors among outpatients. Therefore, our study was one of the few examples in this area.

\section{Conclusion}

Our study demonstrated that malnutrition was independently associated with dementia. We suggest that malnutrition and other geriatric syndromes should be screened routinely in institutions. Patients with poor educational status and functional dependence, urinary incontinence, dementia, and depression seem to be at more risk to have malnutrition and therefore should be paid special attention. Nevertheless, further investigations should be needed to better understand the factors that influence malnutrition in older adults.

\section{Ethics}

Ethics Committee Approval: This study has been evaluated and approved by the local ethics committee (number: 956).

Informed Consent: Four hundred eight patients were included in the study with consent forms.

Peer-review: Internally peer-reviewed.

Financial Disclosure: I have no sources of support to report for this work.

\section{References}

1. Cederholm T, Barazzoni R, Austin P, Ballmer P, Biolo G, Bischoff SC, Compher C, Correia I, Higashiguchi T, Holst M, Jensen GL, Malone A, Muscaritoli M, Nyulasi I, Pirlich M, Rothenberg E, Schindler K, Schneider SM, de van der Schueren MA, Sieber C, Valentini L, Yu JC, Van Gossum A, Singer P. ESPEN guidelines on definitions and terminology of clinical nutrition. Clin Nutr 2017;36:49-64.

2. Jensen GL, Mirtallo J, Compher C, Dhaliwal R, Forbes A, Grijalba RF, Hardy G, Kondrup J, Labadarios D, Nyulasi I, Castillo Pineda JC, Waitzberg D, International Consensus Guideline Committee. Adult starvation and disease-related malnutrition: a proposal for etiology-based diagnosis in the clinical practice setting from the International Consensus Guideline Committee. J Parenter Enteral Nutr 2010;34:156-159.

3. Malafarina $V$, Uriz-Otano $F$, Gil-Guerrero L, Iniesta R. The anorexia of ageing: Physiopathology, prevalence, associated comorbidity and mortality. A systematic review. Maturitas 2013;74:293-302.

4. Wallace J. Malnutrition and enteral/parenteral alimentation, Hazzard's Geriatric Medicine and Gerontology. Chapter 35, 7th edition, New York, The McGraw-Hill Companies, 2017, pp 737.

5. Grabowski DC, Ellis JE. High body mass index does not predict mortality in older people: analysis of the longitudinal study of aging. J Am Geriatr Soc 2001;49:968-979.

6. Norman K, Pichard C, Lochs $H_{1}$ Pirlich M. Prognostic impact of diseaserelated malnutrition. Clin. Nutr 2008;27:5-15.

7. Naseer $M, H$ Forssell, C Fagerström. Malnutrition, functional ability and mortality among older people aged C 60 years: a 7-year longitudinal study. Eur J Clin Nutr 2016;70:399-404.

8. White JV, Guenter $P_{1}$ Jensen $G$, Malone $A$, Schofield $M$, Academy Malnutrition Work Group, A.S.P.E.N. Consensus statement: Academy of Nutrition and Dietetics and American Society for Parenteral and Enteral Nutrition: Characteristics Recommended for the Identification and Documentation of Adult Malnutrition. J Acad Nutr Diet 2012;36:275-283.

9. Martínez-Reig, Aranda-Reneo I, Peña-Longobardo LM, Oliva-Moreno J, Barcons-Vilardell N, Hoogendijk EO, Abizanda P. Use of health resources and healthcare costs associated with nutritional risk: The FRADEA study. Clin Nutr 2018;37:1299-1305.

10. Saka B, Kaya O, Ozturk GB, Erten N, Karan MA. Malnutrition in the elderly and its relationship with other geriatric syndromes. Clin Nutr 2010;29:745748.

11. Agarwa $E$, Miller $M$, Yaxley $A$, Isenring $E$. Malnutrition in the elderly: $A$ narrative review. Maturitas 2013;76:296-302. 
12. Cereda E, Pedrolli C, Klersy C, Bonardi C, Quarleri L, Cappello S, Turri A, Rondanelli M, Caccialanza R. Nutritional status in older persons according to healthcare setting: A systematic review and meta-analysis of prevalence data using MNA. Clin Nutr 2016;35:1282-1290.

13. Volkert D, Beck A, Cederholm T, Cruz-Jentoft A, Goisser S, Hooper $L$, Kiesswetter E, Maggio M, Raynaud-Simon A, Sieber C, Sobotka L, van Asselt D, Wirth $R$, Bischoff S. ESPEN guideline on clinical nutrition and hydration in geriatrics. Clin Nutr 2019;38:10-47.

14. Keskinoglu P, Ucku R, Yener G, Yaka E, Kurt P, Tunca Z. Reliability and validity of revised Turkish version of mini mental state examination (rMMSE-T) in community-dwelling educated and uneducated elderly. Int J Geriatr Psychiatry 2009;24:1242-1250.

15. Durmaz B, Soysal P, Ellidokuz $H$, Isik AT. Validity and reliability of geriatric depression scale-15 (short form) in Turkish older adults. North Clin Istanb 2018;5:216-220.

16. Bozoğlu E, Ozturk A. Definition, Prevalence and etiological factors of malnutrition. Turkiye Klinikleri J Geriatr-Special Topics 2016;2:7-15.

17. Gündüz $E$, Eskin $F$, Gündüz $M$, Bentli $R$, Zengin $Y$, Dursun $R$, İçer $M$, Durgun

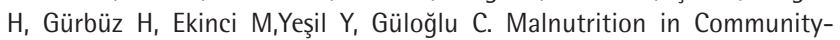
Dwelling Elderly in Turkey: A Multicenter, Cross-Sectional Study. Med Sci Monit 2015;21:2750-2756.
18. Rose A, Thimme A, Halfar C, Nehen HG, Rübben HA. Severity of Urinary Incontinence of Nursing Home Residents Correlates with Malnutrition, Dementia and Loss of Mobility. Urol Int 2013;91:165-169.

19. Soundararajan A, Mathew A, Nanjuudan R, Ganesh A. Association of Geriatric Syndromes with Malnutrition Among Elderly. International Journal of Medical Research \& Health Sciences 2017;6:14-18.

20. Carrión S, Cabré M, Monteis R, Roca M, Palomera E, Serra-Prat M, Rofes L, Clavé P. Oropharyngeal dysphagia is a prevalent risk factor for malnutrition in a cohort of older patients admitted with an acute disease to a general hospital. Clin Nutr 2015;34:436-442.

21. Rullier L, Lagarde A, Bouisson J, Bergua V, Barberger-Gateau P. Nutritional status of community-dwelling older people with dementia: Associations with individual and family caregivers' characteristics. Int Geriatr Psychiatry 2013;28:580-588.

22. Pérez Cruz E, Lizárraga Sánchez DC, Martínez Esteves Mdel R. Association between malnutrition and depression in elderly. Nutr Hosp 2014;29:901906.

23. Kiesswetter $E$, Colombo $M G$, Meisinger $C$, Peters $A$, Thorand $B$, Holle $R$, Ladwig KH, Schulz H, Grill E, Diekmann R, Schrader E, Stehle P, Sieber CC, Volkert D. Malnutrition and related risk factors in older adults from different health-care settings: an enable study. Public Health Nutr 2019;27:1-11. 